\title{
Expanding the Scope of Organizational Behavior Management
}

Relational Frame Theory and the Experimental Analysis of Complex Human Behavior

\section{Steven C. Hayes, Kara Bunting , Scott Herbst , Frank W. Bond \& Dermot} Barnes-Holmes

To cite this article: Steven C. Hayes, Kara Bunting, Scott Herbst , Frank W. Bond \& Dermot Barnes-Holmes (2006) Expanding the Scope of Organizational Behavior Management, Journal of Organizational Behavior Management, 26:1-2, 1-23, DOI: 10.1300/J075v26n01_01

To link to this article: https://doi.org/10.1300/J075v26n01_01

册Published online: 08 Sep 2008.

Submit your article to this journal $\sqsubset$

Џll Article views: 967

Q View related articles $\sqsubset$

Citing articles: 4 View citing articles $匚 \pi$ 


\title{
Expanding the Scope of Organizational Behavior Management: Relational Frame Theory and the Experimental Analysis of Complex Human Behavior
}

\author{
Steven C. Hayes \\ Kara Bunting \\ Scott Herbst \\ Frank W. Bond \\ Dermot Barnes-Holmes
}

SUMMARY. Behavior analysis in general and applied behavior analysis in particular requires a well developed, empirically supported, and useful approach to human language and cognition in order to fulfill its mission of providing a relatively adequate comprehensive account of complex human behavior. This article introduces a series of articles in which the possibilities presented by Relational Frame Theory (RFT) are

Steven C. Hayes, Kara Bunting, and Scott Herbst are affiliated with the University of Nevada, Reno.

Frank W. Bond is affiliated with Goldsmiths College, University of London.

Dermot Barnes-Holmes is affiliated with the National University of Ireland, Maynooth.

[Haworth co-indexing entry note]: "Expanding the Scope of Organizational Behavior Management: Relational Frame Theory and the Experimental Analysis of Complex Human Behavior." Hayes, Steven C. et al. Co-published simultaneously in Journal of Organizational Behavior Management (The Haworth Press, Inc.) Vol. 26, No. 1/2, 2006, pp. 1-23; and: Acceptance and Mindfulness at Work: Applying Acceptance and Commitment Therapy and Relational Frame Theory to Organizational Behavior Management (ed: Steven C. Hayes, Frank W. Bond, Dermot Barnes-Holmes, and John Austin) The Haworth Press, Inc., 2006, pp. 1-23. Single or multiple copies of this article are available for a fee from The Haworth Document Delivery Service [1-800-HAWORTH, 9:00 a.m. - 5:00 p.m. (EST). E-mail address: docdelivery@haworthpress.com].

Available online at http://jobm.haworthpress.com

(C) 2006 by The Haworth Press, Inc. All rights reserved. doi:10.1300/J075v26n01_01 
explored as they apply to issues addressed by Organizational Behavior Management (OBM). RFT provides an empirically useful operant account that has already led to a variety of applied innovations, including several of direct relevance to OBM. doi:10.1300/J075v26n01_01 [Article copies available for a fee from The Haworth Document Delivery Service: 1-800-HAWORTH. E-mail address: <docdelivery@ haworthpress.com> Website: $<$ http://www.HaworthPress.com> () 2006 by The Haworth Press, Inc. All rights reserved.]

KEYWORDS. Relational Frame Theory, Acceptance and Commitment Therapy, cognition in organizational behavior management

Despite over forty years of empirical and conceptual research (Dickinson, 2000), the contribution of behavior analysis to the world of business remains relatively small. Organizational Behavior Management $(\mathrm{OBM})$ receives relatively little attention at the university level or within industrial/organizational psychology $(\mathrm{I} / \mathrm{O})$ as a professional discipline. A simple head-count sheds light on the problem: The Society for Industrial and Organizational Psychology (the American Psychological Association's I/O division) currently has over 6,000 members (http://www.siop. org/media/talking.htm) while the Association for Behavior Analysis' special interest group devoted to I/O work, the OBM Network, is less than $4 \%$ of that size (http://www.obmnetwork.com/membership).

A number of OBM writers have pondered this disparity in impact and influence and a variety of solutions have been offered. Organizational behavior analysts have recommended that behavior analysts soften the use of behavioral language (Brown, 2000), expand upon the variables manipulated (Olson, Laraway, \& Austin, 2001), incorporate the use of more aversive control (Malott, 2002), and expand behavioral psychology to include principles drawn from psychological subfields that have gained a wider audience in the organizational world such as cognitive, personality, and social psychology (Geller, 2002).

The initiating problem in these recommendations is often simple popularity, but that in turn is usually laid at the feet of organizational behavior analysts' inability to deal comfortably and effectively with certain substantive issues. For example, Wiegand and Geller (2005) argue that those working in organizational areas need to understand workers' motivation to produce, and that direct reinforcement models are insufficient. What is recommended as a solution to this problem is a variety of well-established non-behavioral theories: achievement theory (Atkinson, 
1957), self-worth theory (Covington \& Beery, 1976), self-efficacy (Bandura, 1986), and others.

An alternative is to broaden the conceptual base of the field in a more behaviorally based fashion. For example, Olson et al. (2001) properly point out that OBM researchers have failed to exploit establishing operations in their analyses. By including motivational antecedent stimuli, they argue, organizational behavior analysts would increase the sophistication of their analyses and yield more potential interventions.

This is an appealing idea, but as we point out below, it inadvertently says more about the problematic situation behavior analysts' find themselves in than it does about the solutions to these problems. Indeed, Olson et al.'s (2001) call to focus on motivational stimuli was not the first time that Journal of Organizational Behavior Management (JOBM) has published recommendations concerning the use of EO's (e.g., Agnew, 1998). Nevertheless, despite its long history (Michael, 1982) and superficially obvious applied relevance, no empirical articles focusing on the use of the EO appear to have been published in JOBM.

Olson et al. (2001) pointed to a source of this anomaly: although EO manipulations have been successfully carried out in developmentally disabled populations, OBM clients have complex verbal repertoires that may make these kinds of interventions inappropriate. Workers in the organizational area are aware that verbal descriptions may influence the value of particular consequences, sometimes in ways that strengthen undesired behaviors while weakening those desired (see Haas \& Hayes, this volume for an empirical example), but the technical analysis of such situations does not fit the dominant behavior analytic models of such phenomena. As a result, the recommendation to consider EOs amounts to little more than a recommendation to address motivation. We have argued that difficulties in addressing the effects of verbal processes are at the very core of the problems being faced by the field in the first place (see Hayes \& Barnes-Holmes, 2004).

Direct contingency principles are highly relevant to organizational behavior management, which is why OBM has succeeded as well as it has. But the sense that the field has stalled, is too narrow, or needs new concepts from outside behavioral psychology all indicate that the field itself is finding it difficult to use direct contingency principles alone as a model of human behavior. As an applied matter this becomes obvious given the limitations on behavior analysts' ability to alter the immediate environment of organizations, but as a more basic matter it would be true in any situation dominated by complex human behavior. When we are dealing with verbal beings, verbal processes may have important ef- 
fects on the efficacy of environmental manipulations. These processes seemingly involve more than a simple extension of direct contingencies, be they operant or classical. Of course, many behavior analysts would grant that point, but hope to turn to Skinner's analysis of verbal behavior (1957) or of rule-governed behavior (1966) as a solution. Unfortunately this approach also has a relatively weak record of empirical achievement in organizational settings.

The present volume offers another behavior analytic way forward: Relational Frame Theory (RFT; Hayes, Barnes-Holmes, \& Roche, 2001) and its applied extensions, including Acceptance and Commitment Therapy (ACT, said as a single word, not initials; Hayes, Strosahl, \& Wilson, 1999). RFT is behavior analytic in a traditional sense, in that its central claim is simply that a particular kind of operant exists. Nevertheless, it carries with it implications for a very different behavioral approach to complex human behavior.

Now over twenty years old (since its original presentation by Hayes \& Brownstein, 1985), the empirical literature on RFT seems to be reaching a tipping point within behavior analysis. Nearly seventy studies have been published on RFT and fifty on ACT. At least some empirical work has been done on almost every aspect of the basic theory, with extensions into a wide variety of topics faced by organizational behavior analysts and several that are part of traditional I/O psychology but not traditional OBM. These include: motivation (Ju, 2000; Whelan, 2004; Whelan \& Barnes-Holmes 2004); attitude formation to unseen products (Grey \& Barnes, 1996); product preference (Barnes-Holmes, Keane, Barnes-Holmes, \& Smeets, 2000; Smeets \& Barnes-Holmes, 2003); worker burnout (Hayes, Bissett, Roget et al., 2004); work stress and depression (Bond \& Bunce, 2000; Folke \& Parling, 2004); worker disability (e.g., Dahl, Wilson, \& Nilsson, 2004); the ability of workers to learn new tasks (Bond, this volume); worker flexibility and performance (Bond \& Bunce, 2003; see also Bond, this volume); worker disability following injury (McCracken \& Eccleston, 2003); and worker well-being (Donaldson \& Bond, 2004), among several other areas. The research program is gathering steam, with scores of extensions of the theory beginning to be explored. Still, the empirical work is relatively new and several of the most relevant studies are not yet published (e.g., Barnes-Holmes, Milne, \& Barnes-Holmes, 2005; Bond, Flaxman, \& Bunce, 2005; Flaxman \& Bond, 2005).

The purpose of the present collection is to try to show that a comprehensive and experimental behavioral analysis of human language and cognition is here, now, ready for use. It is not a mere conceptual analysis 
and theoretical extension; it is not a promise or hope. Applied extensions are here now as well, and are already having a significant applied impact, including in organizational settings. Rather than expanding the conceptual foundations of the field to include concepts traditionally hostile to behavioral psychology (e.g., Wiegand \& Geller, 2004), this volume presents another alternative: use these ongoing developments in behavior analysis itself as an avenue to broaden the exploration of the psychological issues relevant to organizational issues in OBM.

Organizational behavior analysts who wish to move in this direction face significant challenges, most notably the subtleties of RFT itself. While in one sense based in traditional behavior analysis, RFT and ACT are not initially easy to grasp and they involve new concepts and new techniques that must be mastered. Emerging from clinical behavior analysis, ACT involves clinical sensitivities that not all applied behavior analysts possess even when ACT is used within the scope of practice of OBM. ACT and RFT are self-consciously contextualistic (Hayes, 1993), which can be a challenge for behavior analysts without philosophy of science training, or who have been trained in behavior analysis as a mechanistic approach. Finally, because of its broad implications for the analysis of complex human behavior, RFT leads to a new form of behavior analysis, and it takes time to learn how to include cognitive processes of any kind without resorting to reductionism and mentalism on the one hand (Hayes \& Brownstein, 1986) or to minimization and hand waving on the other.

For all of these reasons, even well-trained behavior analysts cannot instantly become experts at ACT and RFT: a significant intellectual investment is required. The present volume cannot and will not be fully adequate in that regard. Rather, our goal is to make the approach understandable enough that readers can determine for themselves their degree of interest in making such an investment.

This collection contains conceptual, review, and empirical articles on RFT and ACT as they bear on various organizational issues. The present article is by way of an introduction to RFT and ACT. Our goal is to suggest in broad terms why a different approach within behavior analysis is necessary, possible, and fruitful.

\section{RELATIONAL FRAME THEORY}

RFT begins with the empirical fact that human beings readily derive stimulus relations that are not based on the formal properties of related 
events. Stimulus equivalence is perhaps the simplest example, but because equivalence relations can so easily be thought of using existing stimulus class-based concepts from traditional behavior analysis, it can be helpful in promoting understanding to focus on a more complex relation when describing the basic tenets of RFT.

Non-verbal animals can readily be trained to select the smallest or largest object from a stimulus array based on the formal properties of the objects in question. Young children likewise have no difficulty learning such relations. In the pre-school years, however, children begin to apply this comparative relation to events based not on formal properties but based on arbitrary cues to do so. For example, in United States coinage a nickel is formally larger than a dime, but around three or four years of age children generally learn that a dime is larger than a nickel. As this relation is learned, preferences change as well. A young child, having directly experienced that coins can be used to buy things such as candy, will prefer a nickel over a dime because it is larger. A slightly older child will prefer a dime over a nickel. This would be easy to explain if the relative size and relative value was directly learned, but we know that it need not be (Barnes-Holmes, Barnes-Holmes, Smeets, Strand, \& Friman, 2004; Berens \& Hayes, 2005). Children learn a class of comparative relations that can be applied to any set of relata.

RFT takes the view that what children are learning is an arbitrarily applicable relational operant. Most relational operants are likely established initially with non-arbitrary sets, and then extended to arbitrary ones. In effect, children abstract the relational features of the task itself as it comes under the control of arbitrary relational cues (e.g., terms such as "larger than"). Once formed, relational operants (in this case, comparatives) can be applied to any set of relata, based on social whim or convention. In playing a verbal game with a child, for instance, a nickel can be said to be bigger, smaller, or the same as a dime, or bigger, smaller, or the same as a penny-the comparative relation is based on social provision of the proper cues (e.g., "this is bigger than that"), not relative physical size. A properly trained child will derive all of the coherent relations within a comparative network. For example, if a nickel is "bigger than" a penny and "smaller than" a dime, then the child will derive that a dime is bigger than a penny, and a penny is smaller than a dime, even though physically the reverse is true. Significantly, this relation can then alter other behavioral processes. If the child is motivated by a nickel due to direct experience in using nickels to buy candy, he or she will be more motivated by a dime and less by a pennywithout necessarily having used dimes and pennies to purchase items. 
In order to think of this kind of performance as a relational operant (i.e., a class of relational responding under antecedent and consequential control), we need a few technical terms to describe the precise performance being learned. By now these terms are fairly well known in the behavioral literature and book length treatments are available (Hayes et al., 2001), but for purposes of this work it is necessary to briefly define the key terms here.

Arbitrarily applicable relational responding (AARR) has three important properties: mutual entailment, combinatorial entailment, and the transformation of stimulus functions. The relational properties are regulated by relational contextual cues (" $\mathrm{C}_{\text {rel }}$ "); the functional properties are regulated by functional contextual cues (" $\mathrm{C}_{\text {func }}$ "). These five terms comprise the basic vocabulary of RFT.

\section{Mutual Entailment and Combinatorial Entailment}

Given a relationship between two novel stimuli A and B, human beings will typically derive a relationship between $\mathrm{B}$ and $\mathrm{A}$. For example, if we teach a human being to pick $B$ from a set of stimuli when $A$ is presented, the human being will now also likely pick A from a set of stimuli if B is presented. This bi-directional quality of relational responding is termed "mutual entailment." Even 16 month old human infants exhibit this response feature (Lipkens, Hayes, \& Hayes, 1993). Combinatorial entailment means that if $\mathrm{A}$ is related to $\mathrm{B}$, and $\mathrm{B}$ is related to $\mathrm{C}$, then $\mathrm{A}$ and $\mathrm{C}$ are mutually related. RFT researchers have shown that the processes of mutual and combinatorial entailment apply to virtually any specifiable relation, such as "better than," "comes after," "opposite to" and so on (Hayes et al., 2001). For example, a verbally competent person told that A comes before B would derive that B comes after A. Because bi-directionality is not a necessary quality of all sequences of action, it is critical that AARR come under contextual control. In the absence of contextual control, any chain would be inverted for example, leading frequently to disastrous consequences (put on a parachute before jumping could be inverted to jumping before putting on a parachute). In non-arbitrary relations that contextual control is exerted by the form of the relata themselves (e.g., a child quickly learns that an apple is heavier than a sheet of paper). In AARR it is exerted by $\mathrm{C}_{\text {rel }}$ cues that indicate that a particular form of AARR is likely to be reinforced in a given context. A child who is told that neighbor A's dog is much more likely to bite than neighbor B's dog may approach the latter animal more readily than the former. 


\section{The Transformation of Stimulus Functions}

When stimuli are framed relationally through processes of learned mutual and combinatorial entailment, a change in the function of one stimulus in a network may result in changes in the function of other stimuli modified via the derived relation between them. RFT calls this process "the transformation of stimulus functions." The word "transformation" is necessary because these changes in function are relational, not merely associative. For example, suppose a person has learned the comparative relational network corresponding to the coinage example used earlier: $\mathrm{A}<\mathrm{B}<\mathrm{C}$. Imagine that $\mathrm{B}$ is given a $\mathrm{CS}$ function through classical conditioning, such that $\mathrm{B}$ is paired with shock and as a result now elicits autonomic arousal as measured by skin conductance. In a proper context that selects this arousal function $\left(\mathrm{C}_{\text {func }}\right)$ we would expect that $\mathrm{A}$ will now elicit small amounts of arousal and $\mathrm{C}$ will elicit large amounts-perhaps even more than the stimulus directly paired with shock. Indeed, this exact finding has already been demonstrated (Dougher, Hamilton, Fink, \& Harrington, 2005). It is also important to understand that transformations of stimulus functions are under contextual control-otherwise when two stimuli were related as the same, the two stimuli would become one. This is not what occurs. We might salivate when we see or hear the word "lemon" but we would not try to eat the word (note, however, that the appropriate contextual control may be absent initially for a young child who may attempts to lick a picture of ice-cream, for example).

\section{Relational Frames}

From an RFT point of view, verbal events are events that have their functions because they participate in relational frames. Relational frames are specific classes of AARR that show the contextually controlled properties of mutual and combinatorial entailment and the transformation of stimulus functions, not due solely to formal properties or to direct training with the stimuli involved, but due to a history of such relational responding and the presence of contextual cues that evokes this pattern of responding.

\section{WHY RELATIONAL FRAMES LEAD TO A NEW BEHAVIORAL PRINCIPLE}

Relational operants are argued to emerge due to operant contingencies. No new principles are thought to be needed to account for the de- 
velopment of relational frames per se. They are said to be "generalized" or "overarching" only in the non-technical sense that these purely functional response classes cannot be defined by the formal or topographical properties of a given instance (thus the metaphor of a "frame"). A number of empirically examined features suggest their operant nature (e.g., development, antecedent control, consequential control, shapability: see Hayes et al., 2001 and Barnes-Holmes et al., this volume), but perhaps the best evidence is the recent demonstration that they can be established through contingencies of reinforcement when they are absent. For example, young children who do not have frames of opposition (Barnes-Holmes et al., 2004) or comparison (e.g., Barnes-Holmes et al., 2004; Berens \& Hayes, 2005) can be taught these frames through multiple exemplar training that reinforces specific instances.

What makes relational framing so important for behavior analysis is that it implies a fundamentally new behavioral principle. Consider the experiment mentioned earlier regarding the arbitrary relational network $\mathrm{A}<\mathrm{B}<\mathrm{C}$. If $\mathrm{B}$ acquired an eliciting function directly $\mathrm{C}$ may now elicit a greater conditioned response than $\mathrm{B}$ by derivation; if $\mathrm{B}$ acquired a discriminative function for, say, responding of a given rate, A would lead to lower rate responding and $\mathrm{C}$ to higher rate responding (Dougher et al., 2005; for similar studies see Dymond \& Barnes, 1995, 1996; Roche \& Barnes, 1997; Roche, Barnes-Holmes, Smeets, Barnes-Holmes, \& McGeady, 2000 among several others). This means that many of the antecedent, consequential, and motivational functions of such importance to applied behavior analysis, including organizational behavior management, may not be direct as they appear, but instead are the results of an interaction between direct and derived functions.

RFT argues that the process of relational framing is learned. If that is correct, these situations involve a learned behavior (relational operants) fundamentally altering other behavioral processes. No existing behavioral term describes such an effect. For example, while a discriminative stimulus must be learned, the process of discrimination learning is not. If relational frames can establish, augment, or diminish reinforcers, punishers, discriminative stimuli, conditioned stimuli, establishing stimuli, and so on, a new behavioral process has been identified, and it harms the precision of behavior analysis to stretch existing terms to describe it.

This new process does not explain relational framing-it is an empirical implication of it. The new principle is indicated in RFT by the qualifier "relational" or "verbal." For example, the stronger skin conductance response to $\mathrm{C}$ than $\mathrm{B}$ in an $\mathrm{A}<\mathrm{B}<\mathrm{C}$ network with $\mathrm{B}$ being di- 
rectly paired with shock is not a CS function. $\mathrm{C}$ does not have the history for a classically conditioned function, and stimulus generalization cannot explain why subjects treat it as a stronger CS than the CS directly trained. Instead, C is a "relational CS" or a "verbal CS." (Two terms are used here because both have been used in RFT writings; each has benefits and weaknesses, and the field itself has not yet shown a preference for one over the other. In the rest of this paper, however, we will use the term "relational.")

The empirical evidence for relational operants is by now extensive, covering almost every kind of behavioral function. The literature has demonstrated relational discriminative stimuli, relational reinforcers, relational conditioned stimuli, and relational establishing stimuli, among others (e.g., Dougher, Auguston, Markham, Greenway, \& Wulfert, 1994; Dymond \& Barnes, 1994, 1995, 1996; Hayes, Brownstein, Devany, Kohlenberg, \& Shelby, 1987; Hayes, Kohlenberg, \& Hayes, 1991; Roche et al., 2000). Given the ubiquity of human language itself, these findings cause RFT to take behavior analysis into a new, post-Skinnerian era. It is post-Skinnerian in several senses, but what we are referring to here is the way that behavioral thinking must be reworked to include relational operants side by side with the discussion of direct contingencies whenever complex human behavior is considered.

Skinner (1945/1972) claimed that while one could do a scientifically valid analysis of thoughts and feelings, one did not need to do so to understand behavior because the same contingencies that evoked overt behavioral events were responsible for private events. In the case of non-verbal organisms this analysis seems correct, but RFT suggests that it is not correct for verbal organisms. Human language and cognition is not merely another form of contingency-shaped behavior, even though it is itself shaped by contingencies, because human language and cognition operates on other behavioral processes. If such recursive operants exist, due to their spread of application it will be impossible to fully understand human behavior without understanding the derived relations and functional transformations that apply to any given event. For example, suppose a person is being paid for doing a job. It may not be enough to understand the directly conditioned reinforcing effects of the pay received in order to understand performance. We may also need to know what that pay is related to. Does the worker consider it "fair," is it "more than" what others are getting or "more than" what was "expected," does it suggest that the worker is "being bossed around" or is a "management stooge" and so on. The scare quotes put around various terms in the previous sentence are there to indicate some of the many verbal relations 
that might alter how pay functions. The Haas and Hayes study (this volume) shows that exact process, in which formal feedback showing that performance is successful makes it less likely for the workers to persist in successful performance. There is little in direct contingency thinking alone that could explain such a process, but it is expected and understandable once relational operants are included in the analysis.

Although relational framing operates on other behavioral processes, this does not mean that relational operants are causes. In behavior analysis all causes must ultimately be outside the behavioral system being analyzed (Hayes \& Brownstein, 1986). The reason for this is philosophical. Behavior analysis seeks the prediction-and-influence of psychological events, and it is not possible to influence or change psychological events except by changing the context of action. Thus, unlike traditional mechanistic cognitive psychology, RFT never leads to the conclusion that cognitive processes cause overt behavior. From an RFT perspective, cognitive processes are behavior. Within RFT it is only history and context that creates sequences of actions that alter psychological functions. But, unlike Skinner (1945), RFT suggests that we must account for human behavior by exploring the interaction between two contingency streams: one direct and one arbitrary and relational. Understanding language and cognition thus becomes essential to understanding human behavior generally. If that point is admitted, then behavior analysis itself has fundamentally changed.

While there are clear signs that a tipping point is being reached (indeed this collection is one such sign) it is understandable that RFT has been slow to penetrate behavior analysis. An implication of RFT is that every behavioral finding must be reexamined and potentially reworked as it applies to verbal humans. That is a daunting insight, because it suggests that behavior analysis is much farther away than would be wished from its ultimate goal of providing a relatively adequate account of complex human behavior. It is also exciting, however, since RFT suggests many non-obvious ways to train tasks effectively, to generalize learning, to create more flexible repertoires, and to motivate performance. As these insights have been explored, many of them are producing significant applied gains. Because this extension process is so far relatively narrowly focused, it could be that significant behavioral gains can be achieved in many areas of importance to applied behavior analysis as the implications of RFT are worked out. 


\section{ACCEPTANCE AND COMMITMENT THERAPY}

Acceptance and Commitment Therapy is the first applied approach based firmly on RFT. It is not our purpose to describe ACT in detail here since several book length treatments are now available (Eifert \& Forsythe, 2005; Hayes \& Strosahl, 2004; Hayes et al., 1999). Rather, it is being raised here because it shows how RFT can lead into fundamentally new avenues that have proven to be empirically useful, including work in organizational settings or on organizational topics (e.g., Bond, 2005; Bond \& Bunce, 2000; Bond \& Hayes, 2002; Hayes, Bissett et al., 2004).

\section{Experiential Avoidance and the Spread of Pain}

Relational frames allow human beings to have aversive experiences even when there is nothing directly aversive present in the environment. For instance, thoughts about being fired from a past job may be cued by the daily commute, feelings of anxiety, the want ads in the newspaper, briefcases in a store window, a phrase overheard in conversation, or any of thousands of such events that might evoke a relational frame that includes the past job loss. The relational responses, in turn, may occasion various response functions, such as arousal, emotional responses, or sequences of thought. This means that, unlike non-verbal organisms, humans cannot fully control pain by avoiding situations in which some kind of aversive stimulation occurred. Derived stimulus functions can transfer aversive functions to almost any situation.

In self-defense human beings often attempt to regulate negative events by targeting the psychological results because targeting environmental situations is not reliable. In ACT this is termed "experiential avoidance"-the tendency to control the form, frequency, or situational sensitivity of private events even when attempts to do so cause behavioral harm. This coping strategy is one of the most pathological processes known (Hayes et al., 1996) because it means that the person's own history is now a kind of enemy. For example, suppose remembering a past firing is aversive but almost any event evokes the memory. The person might attempt to suppress the thought of the past firing, or to eliminate the sense of pain that comes from that memory. Unfortunately, deliberate attempts to control private events tend, over time, to give them greater functional importance and thus to establish them as more evocative. The relational nature of the verbal rule "don't think about $\mathrm{x}$ " is likely ultimately to cue the very thoughts that are being 
avoided, since " $x$ " is in a relational frame with the avoided event. Various avoidance methods (e.g., distraction) will reduce the aversive thoughts and feelings, but only for a short time. When the impact of the rule is checked ("is it gone now?") the avoided event is likely to reoccur, meaning that avoidance rules are serving as a $\mathrm{C}_{\text {func }}$ for $\mathrm{x}$-perversely amplifying the very functions this avoidance rule seeks to reduce. As a result of a kind of behavioral trap, experiential avoidance may ultimately strengthen the relations and functions involving the avoided events in question. Workers may become virtually obsessed with past failures and the rightness or wrongness of their treatment. Stress, burnout, apathy, depression, and poor productivity may be the result.

A large and growing literature shows that experiential avoidance leads to narrow, rigid, and ineffective repertoires (Hayes, Strosahl et al. 2004). This has been shown in a wide variety of contexts, from educational performance to psychological health, but it has also been shown in organizations. Bond and Bunce (2003) measured the keystroke errors made by call center employees and found measures of acceptance, defusion and valued action to be more predictive of accuracy, over one year, than measures of job control, negative affectivity, and locus of control alone. Psychological flexibility was also demonstrated to predict mental health and job performance (as measured by errors as well as self-report) one year later. In the present volume, Bond shows that these processes can even help explain how much workers learn. If it is unacceptable to feel, think, and remember aversive events, then even learning is difficult because attempting to learn new things is awkward, uncomfortable, and subjects one to evaluation. RFT suggests that experiential avoidance is a natural result of human language and cognition that is then exacerbated by the culture. Fortunately it also suggests steps to take to solve this problem, as we will discuss shortly.

\section{“Living in Your Head”: The Domination of Derived Functions}

Even the simplest verbal problem solving task relies on relational frames. The problem solving sentence "if I do this then I'll get that which is an improvement" contains relational frames of coordination (e.g., "this" is in a frame of coordination with the events it refers to), time or contingency (e.g., "if . . then"), and comparison (e.g., "improvement"). This idea is similar to Skinner's view of the use of verbal rules ("contingency specifying stimuli") to solve problems (Skinner, 1966). What RFT adds are (a) the processes needed to specify what it means to "specify," (b) the history needed to produce these processes, 
and (c) in its emphasis on entailment and the transformation of stimulus function, the precise behavioral implications of such a repertoire.

This repertoire is enormously useful to human beings, but the same verbal abilities that allow human beings to imagine futures that have not been experienced in order to make beneficial choices in the present may also allow pathological events to occur. Humans can respond to imagined fears of the future, or to comparisons between the present and what might have been, or to purely verbal expectations and standards. The transformation of stimulus function properties of language means that evaluations may cause the present to be experienced as negative. One can easily picture reporting satisfaction with one's job until one discovers that the person in the next cubicle makes twice as much for the same work. No properties in the physical environment have changed, but the evaluative frames verbal relations enable quickly allow one to experience one's job as unrewarding, and behavior may change accordingly.

The problem is that language is so generally useful that verbal relations such as these may come to control more and more behavior, even when other sources of behavioral regulation (e.g., direct contingency control) would lead to more flexible and successful behavior in a given context. In ACT this is termed "cognitive fusion"-the domination of verbal regulatory processes over other behavioral processes based on contact with the stimulus functions produced by derived relational responding rather than contact with what is directly experienced. In addition to the kinds of direct contingencies usually studied by behavior analysts, in the area of language and cognition an additional event always directly available to be contacted is the ongoing processes of relating itself. For example, if " $\mathrm{X}$ is better than $\mathrm{Y}$ " there is a tendency simply to respond to $\mathrm{Y}$ as less preferred than $\mathrm{X}$, to the exclusion of direct experiences with either $\mathrm{X}$ or $\mathrm{Y}$, and to the exclusion of noticing that what actually happened in the moment was a relational action (to put it into words for the sake of clarification, "now I am having the thought that $\mathrm{X}$ is better than Y"). Said more colloquially, RFT supports that idea that humans often begin to "live in their head" and diminish functional contact with the present moment, including contact with ongoing behavioral processes.

RFT suggests that experiential avoidance and cognitive fusion are likely to be pervasive but also detrimental because the repertoire that results is narrow, rigid, and relatively unsuccessful. This presents a conundrum because even if it were possible to eliminate these language processes, it would not be desirable because it is these very same processes that enable human abilities like problem solving. 


\section{Solving the Problem of Language}

Acceptance and Commitment Therapy incorporates techniques designed to solve the problems that runaway language functions present. By recontextualizing language and cognition, ACT can alter the functions of human private events, promoting more psychological flexibility.

Cognitive defusion. Because of the way language functions, derived relations structure the stimulus functions of the environment, but often without people noting the process through which this transformation occurs. ACT techniques target the way human beings relate to language, so that the process of language becomes more evident and the content of language becomes somewhat less important. This is called "cognitive defusion." In technical terms, cognitive defusion is a $\mathrm{C}_{\text {func }}$ technique, not a $\mathrm{C}_{\text {rel }}$ technique, which is designed to alter the functional importance of language and cognition in given contexts, even when the relational network remains intact.

One such technique is the Milk, Milk, Milk exercise, taken from Titchener (1916, p. 425). In this exercise, participants discuss all the perceptual properties that are brought up by saying the word such as its color and texture, taste, etc. Participants then say the word out loud, rapidly and repeatedly for about 45 seconds. In this short time the meaning of the word disintegrates and participants are mostly noticing a sound. This exercise is usually repeated with a word more relevant to areas of concern; in the workplace something like "dumb" or "deadline" might be appropriate. The exercise is designed to reduce the transformations of stimulus functions that occur routinely in human language without having to change the form or eliminate the presence of specific verbal events. The data suggest that this is exactly what happens as a result of the procedure (Masuda et al., 2004)

Scores of defusion procedures have been developed. Unlike cognitive therapy, which seeks to change the form of difficult thoughts but often seems only to make them more impactful, ACT undermines the domination of human thought when thought is not helpful, so that direct contingencies can begin to exert more control over behavior.

Acceptance. RFT suggests that verbally able beings will experience some private events as aversive, even in the absence of anything aversive in the environment. Furthermore, it suggests that the nature of language is such that it is possible for many things to cue these aversive private events, and attempts to suppress them are likely to be unsuccessful. 
ACT teaches clients to accept difficult feelings instead. This undermines their behavior regulatory effects, and diminishes the self-amplifying avoidance rules that prevent exposure, and paradoxically increase the importance of painful emotions. A wide variety of acceptance methods are trained: people are taught to notice specific bodily sensations and to feel them deliberately; they learn to note related events that "come to mind," and they learn to seek out rather than to avoid exposure opportunities.

To ask people to accept thoughts like "I'm going to have a heart attack if I keep working here" without defusion would not be helpful because in effect, that would be asking someone to accept the reality that his or her job will cause a heart attack. In a context where the literal functions of language have been loosened, however, accepting difficult private experiences may be possible and useful. ACT asks participants to accept events as they are, not as they say they are, meaning that it facilitates the experience of difficult thoughts as difficult thoughts, not as reality.

Values. Although much of ACT addresses the detrimental elements of language and cognition, ACT also supports the development of verbally constructed contingencies that are likely to have significant positive impact on behavior. RFT suggests that human beings are able to construct verbal futures that can alter the function of a myriad of other events they are related to, and ACT can utilize this property of language to change the functions of tasks. It does so by emphasizing the human ability to link current behavior to desired global qualities of ongoing actions (e.g., being an honest or loving person). In a word, ACT teaches people how to use values.

Language and cognition allow human beings to work for verbally constructed futures that have never occurred, and thus they can be utilized to create behavior even when consequences are very distant or have never been experienced. Someone who volunteers for a non-profit organization that works to promote world peace or environmental improvement, is not doing it to get paid and the work per se may not be reinforcing. What is important is that the work is about something-that is, it fits into an unfolding pattern of progress toward a verbally specified future.

ACT distinguishes between concrete goals, which are achievable and obtainable, and values, which can only be instantiated as a quality of an ongoing action. This discrimination is useful in that values can guide behavior for an infinite length of time-they are never achieved, they only apply to actions in the moment. For instance, a person may choose 
to value positive and supportive relationships with co-workers, but this is never achieved in a final way. One would have to make choices with regard to this value every day at work. People may create verbal goals that can be worked for and achieved as part of a valued direction, but values continue to define new goals.

Distinguishing values and goals and defining values may also change the context in which individuals evaluate their work. Although it seems likely that values play a role in the jobs people select initially, individuals may lose contact with what they value in their work over time as they evaluate actual events against the specific verbal futures (goals) they construct within those values. For instance, one might become a lawyer because one valued fair treatment for other human beings. One might then take a job one believed would serve these ends, but might soon see that justice often does not prevail. If the job is all about goals this could be very discouraging, but if it is about values the achievement of justice in an individual case is not the only issue: Reinforcement may be achieved by behaving in accord with one's value (i.e., working hard to achieve justice as a value even if one sometimes fails in particular cases), rather than always having to achieve a specific goal (i.e., justice in every case).

When cognitive defusion work has recontextualized some of the verbal barriers to valued action, ACT exercises allow the construction of new valued futures. In the example mentioned above, defusion work would be important at the level of verbal barriers that took the form of thoughts like "I can't enjoy my work because the justice system doesn't work." Workers may often experience their organizations as valuing different things than they value, and defusion from verbal constructions around this perceived conflict creates a context where new relationships to work can be formed. Verbal relations that can be more powerful in motivating behavior can be constructed at the level of the individual and in the relationship of the individual to the organization. In almost any organization and position, people have many opportunities to serve something they might choose to value; for example, concepts like contribution or relationships with co-workers would be possible values in most jobs. In addition to clarifying individual values with regard to work, ACT interventions can involve participants in constructing what they value together as an organization. Aligning individual and organizational values in this manner can situate individual values in the context of organizational values such that they are experienced as supporting and augmenting each other, rather than competing. This construction of organizational values will unite individuals within an 
organization around helping their organization function in accord with valued ends. It may also facilitate their perception of individual and organizational values alignment.

\section{Example of the Application of ACT: Job Stress and Disability}

One of the most common complaints people may voice about jobs is that they are stressful. A survey by Yale University reported that $29 \%$ of workers reported feeling "quite a bit or extremely" stressed at work (Barsade, Wiesenfeld, \& the Marlin Company, 1997). Stressors such as a lack of job control, poor social support, role conflicts, and work overload are reliable predictors of a variety of undesirable psychological and behavioral results, including anxiety, decreased productivity, and absenteeism (e.g., Cox, Griffiths, Barlowe, Randall, Thomson, \& RialGonzalez, 2000). Furthermore, the reported experience of stress may predict a number of other health and work related problems.

Individuals generally consider situations stressful when they evaluate them as threatening their well being because they overwhelm their available resources (Folkman \& Lazarus, 1988). This conceptualization offers two possible targets for stress, the stressor and the evaluation of the stressor. The nature of language is such that the second target is often overlooked when interventions for stress are sought. By addressing cognitive fusion, however, ACT may allow for reductions in reported stress even when changes to the organizational environment are impossible. ACT argues that thoughts like "I can't cope with this job anymore" don't need to change to reduce stress, rather only the context in which these thoughts are held needs to change, and cognitive defusion techniques aim to do this.

This conception was tested in a group-based ACT intervention implemented in a media organization. The intervention was delivered in the form of three 3-hour sessions, two on consecutive weeks, which introduced the techniques, and one 3-months later which was intended to address any difficulties participants had experienced after implementing the new strategies. As compared to a wait list control and to training in taking behavioral steps to control sources of stress in the workplace, ACT was shown to better improve general mental health and reduce stress and depression. Interestingly, it increased actual workplace innovation as much as the previously validated behavioral intervention with that target (Bond \& Bunce 2000; Flaxman \& Bond, 2005). Increased acceptance, defusion and valued action were demonstrated to be the processes resulting in these positive changes. They were also shown to 
account significantly for medium-term changes in a cognitive therapy worksite intervention (Flaxman \& Bond, 2005), which suggests one important reason why cognitive change interventions may actually work.

Similarly, a one day, 6-hour ACT intervention with drug and alcohol counselors resulted in lower job burnout among counselors three months later, as well as higher reported levels of "sense of personal accomplishment" in their jobs (Hayes, Bissett et al., 2004). The ACT intervention also significantly decreased the counselors' negative stigmatizing beliefs about clients, and process analysis demonstrated that defusion from negative thoughts about difficult clients was the process by which positive changes occurred.

In another related study, a 4-hour ACT intervention with workers at risk for permanent disability due to pain and burnout resulted in only a few missed days in the ACT group over six months, versus almost nearly 20 times that in the treatment as usual group (Dahl, Wilson, \& Nilsson, 2004). Comparable results have been found for workers on sick leave related to depression (Folke \& Parling, 2004). Thus, ACT is already known to be relevant to organization issues such as burnout, stress, disability, and sense of accomplishment.

\section{LOOKING TO THE FUTURE}

While RFT interventions are already having a significant impact, the present volume shows that the surface has just begun to be scratched. In this work we will consider such issues as goal setting, feedback, task descriptions, and workers' ability to learn as examples of some of the organizational phenomena that can be addressed using RFT. In fact, RFT potentially has implications for any complex form of human behavior that may involve verbal processes.

RFT provides a technical analysis that makes sense of many of the empirically supported ideas in I/O psychology and general psychology, but without requiring the abandonment of the core principles of behavior analysis. Because of this feature, adopting an RFT account facilitates the utilization of behavior analytic research outside of behavior analysis and more communication between behavior analysis and other areas of psychology. This is already evident with ACT, in that cognitive theorists and therapists have found a great deal to discuss in ACT (e.g., Ellis, 2005). Independent of other areas of psychology, RFT is also a generative source for enhancing current interventions and creating new ones. Involving an RFT analysis of verbal behavior connects OBM to a 
clinical behavior analytic tradition with diverse implications for intervention in a setting comprised of verbally able humans. For all of these reasons, RFT seems likely to enhance OBM. As this collection will help show, it is already the case, even though these implications have just begun to be explored.

\section{REFERENCES}

Agnew, J. L. (1998). The establishing operation in organizational behavior management. Journal of Organizational Behavior Management, 18 (1), 7-19.

Atkinson, J. W. (1957). Motivational determinants of risk-taking behavior. Psychological Review, 64, 359-372.

Bandura, A. (1986). Social foundations of thought and action: A social cognitive theory. New Jersey: Prentice Hall.

Barnes-Holmes, D., Keane, J., Barnes-Holmes, Y., \& Smeets, P. M. (2000). A derived transfer of emotive functions as a means of establishing differential preferences for soft drinks. The Psychological Record, 50, 493-512.

Barnes-Holmes, D., Milne, R., \& Barnes-Holmes, Y. (2005). The implicit relational assessment procedure (IRAP): Assessing explicit and implicit attitudes to autism among professionals with experience or no experience of autistic spectrum disorder. Unpublished manuscript.

Barnes-Holmes, Y., Barnes-Holmes, D., Smeets, P. M., Strand, P., \& Friman, P. (2004). Establishing relational responding in accordance with more-than and lessthan as generalized operant behavior in young children. International Journal of Psychology and Psychological Therapy, 4, 531-558.

Barsade S., Wiesenfeld B., \& The Marlin Company (1997). Attitudes in the American workplace III. New Haven, CT: Yale University School of Management.

Berens, N. M., \& Hayes, S. C. (2005). Arbitrarily applicable comparative relations: Experimental evidence for a relational operant. Manuscript submitted for publication.

Bond, F. W. (2005). ACT for stress. In S. C. Hayes and K. D. Strosahl (Eds.), A practical guide to Acceptance and Commitment Therapy (pp. 275-293). New York: Springer-Verlag.

Bond, F. W., \& Bunce, D. (2000). Mediators of change in emotion-focused and problem-focused worksite stress management interventions. Journal of Occupational Health Psychology, 5, 156-163.

Bond, F. W., \& Bunce, D. (2003). The role of acceptance and job control in mental health, job satisfaction, and work performance. Journal of Applied Psychology, 88, 1057-1067.

Bond, F.W., Flaxman, P.E., \& Bunce, D. (2005). Mediators and moderators of a work reorganization intervention: The effect of an individual characteristic on the success of work redesign. Manuscript submitted for publication.

Bond, F. W., \& Hayes, S. C. (2002). ACT at work. In F. Bond \& W. Dryden (Eds.), Handbook of brief cognitive behaviour therapy (pp. 117-140). Chichester, England: Wiley. 
Brown, P. L. (2000). Communicating the benefits of the behavioral approach to the business community. Journal of Organizational Behavior Management, 20(3/4), 59-72.

Covington M. V., \& Beery, R. G. (1976). Self-worth and school learning. New York: Holt, Rinehart, and Winston.

Cox, T., Griffiths, A., Barlowe, C., Randall, R., Thomson, L., \& Rial-Gonzalez, E. (2000). Organisational interventions for work stress: A risk management approach. Norwich UK: Health and Safety Executive/Her Majesty's Stationary Office.

Dahl, J., Wilson, K. G., \& Nilsson, A. (2004). Acceptance and Commitment Therapy and the treatment of persons at risk for long-term disability resulting from stress and pain symptoms: A preliminary randomized trial. Behavior Therapy, 35, 785-802.

Dickinson, A. M. (2000). The historical roots of organizational behavior management in the private sector: The 1950s-1980s. Journal of Organizational Behavior Management, 20(3/4), 9-58.

Donaldson, E., \& Bond, F.W. (2004). Psychological acceptance and emotional intelligence in relation to workplace well-being. British Journal of Guidance and Counseling, 34, 187-203.

Dougher, M. J., Hamilton, D., Fink, B., \& Harrington, J. (2005). Transformation of the discriminative and eliciting functions of generalized relational stimuli. Manuscript submitted for publication.

Dougher, M. J., Auguston, E. M., Markham, M. R., Greenway, D. E., \& Wulfert, E. (1994). The transfer of respondent eliciting and extinction functions through stimulus equivalence classes. Journal of the Experimental Analysis of Behavior, 62, 331-351.

Dymond, S., \& Barnes, D. (1994). A transfer of self-discrimination response functions through equivalence relations. Journal of the Experimental Analysis of Behavior, 62, 251-267.

Dymond, S., \& Barnes, D. (1995). A transformation of self-discrimination response functions in accordance with the arbitrarily applicable relations of sameness, morethan, and less-than. Journal of the Experimental Analysis of Behavior, 64, 163-184.

Dymond, S., \& Barnes, D. (1996). A transformation of self-discrimination response functions in accordance with the arbitrarily applicable relations of sameness and opposition. The Psychological Record, 46, 271-300.

Eifert, G., \& Forsyth, J. (2005). Acceptance and Commitment Therapy for anxiety disorders. Oakland: New Harbinger.

Ellis, A. (2005). Can Rational-Emotive Behavior Therapy (REBT) and Acceptance and Commitment Therapy (ACT) resolve their differences and be integrated? Journal of Rational-Emotive and Cognitive-Behavior Therapy, 23, 153-168.

Flaxman, P.E., \& Bond, F.W. (2005). Mechanisms of change in Acceptance and Commitment Therapy and Cognitive Therapy: Findings from a worksite stress management intervention. Manuscript submitted for publication.

Folke F., \& Parling, T. (2004). Acceptance and Commitment Therapy in group format for individuals who are unemployed and on sick leave suffering from depression: A randomized controlled trial. Unpublished thesis, University of Uppsala, Uppsala, Sweden. 
Folkman, S., \& Lazarus, R. S. (1988). The relationship between coping and emotion: Implications for theory and research. Social Science \& Medicine, 26 (3), 309-317.

Geller, E. S. (2002). Should organizational behavior management expand its content? Journal of Organizational Behavior Management, 22(2), 13-30.

Grey, I., \& Barnes, D. (1996). Stimulus equivalence and attitudes. The Psychological Record, 46, 243-270.

Hayes, S. C. (1993). Analytic goals and the varieties of scientific contextualism. In S. C. Hayes, L. J. Hayes, H. W. Reese, \& T. R. Sarbin (Eds.), Varieties of scientific contextualism (pp. 11-27). Reno, NV: Context Press.

Hayes, S. C., \& Barnes-Holmes, D. (2004). Relational operants: Processes and implications: A response to Palmer's review of relational frame theory. Journal of the Experimental Analysis of Behavior, 82, 213-224.

Hayes, S. C., Barnes-Holmes, D., \& Roche, B. (2001). Relational frame theory: A post-Skinnerian account of human language and cognition. New York: Kluwer Academic/Plenum Publishers.

Hayes, S. C., Bissett, R., Roget, N., Padilla, M., Kohlenberg, B. S., Fisher, G., Masuda, A., Pistorello, J., Rye, A. K., Berry, K., \& Niccolls, R. (2004). The impact of acceptance and commitment training and multicultural training on the stigmatizing attitudes and professional burnout of substance abuse counselors. Behavior Therapy, $35,821-835$.

Hayes, S. C., \& Brownstein, A. J. (May, 1985). Verbal behavior, equivalence classes, and rules: New definitions, data, and directions. Invited address presented at the Association for Behavior Analysis, Columbus, $\mathrm{OH}$.

Hayes, S. C., \& Brownstein, A. J. (1986). Mentalism, behavior-behavior relations and a behavior analytic view of the purposes of science. The Behavior Analyst, 9, 175-190.

Hayes, S. C., Brownstein, A. J., Devany, J. M., Kohlenberg, B. S., \& Shelby, J. (1987). Stimulus equivalence and the symbolic control of behavior. Mexican Journal of Behavior Analysis, 13, 361-374.

Hayes, S. C., Kohlenberg, B. K., \& Hayes, L. J. (1991). The transfer of specific and general consequential functions through simple and conditional equivalence classes. Journal of the Experimental Analysis of Behavior, 56, 119-137.

Hayes, S. C., \& Strosahl, K. D. (2004). A practical guide to Acceptance and Commitment Therapy. New York: Springer-Verlag.

Hayes, S. C., Strosahl, K., \& Wilson, K. G. (1999). Acceptance and Commitment Therapy: An experiential approach to behavior change. New York: Guilford Press.

Hayes, S. C., Wilson, K. W., Gifford, E. V., Follette, V. M., \& Strosahl, K. (1996). Experiential avoidance and behavioral disorders: A functional dimensional approach to diagnosis and treatment. Journal of Consulting and Clinical Psychology, 64, 1152-1168.

Ju, W. C. (2000). Toward an empirical analysis of verbal motivation: A possible preparation for distinguishing discriminative and motivational functions of verbal stimuli. Unpublished doctoral dissertation. University of Nevada, Reno.

Lipkens, G., Hayes, S. C., \& Hayes, L. J. (1993). Longitudinal study of derived stimulus relations in an infant. Journal of Experimental Child Psychology, 56, 201-239.

Malott, R. W. (2002) What OBM needs is more Jewish mothers. Journal of Organizational Behavior Management, 22(2), 71-87. 
Masuda, A., Hayes, S. C., Sackett, C. F., \& Twohig, M. P. (2004). Cognitive defusion and self-relevant negative thoughts: Examining the impact of a ninety year old technique. Behaviour Research and Therapy, 42, 477-485.

McCracken, L. M., \& Eccleston, C. (2003). Coping or acceptance: What to do about chronic pain. Pain, 105, 197-204.

Michael, J. L. (1982). Distinguishing between discriminative and motivational functions of stimuli. Journal of the Experimental Analysis of Behavior, 37, 149-155.

OBM Network Web Page (March, 2005). Retrieved from http://www.obmnetwork.com/ membership/directory/ on July 25, 2005.

Olson, R., Laraway, S., \& Austin, J. (2001). Unconditioned and conditioned establishing operations in organizational behavior management. Journal of Organizational Behavior Management, 21(2), 7-36.

Roche, B., \& Barnes, D. (1997). A transformation of respondently conditioned sexual arousal functions in accordance with arbitrary relations. Journal of the Experimental Analysis of Behavior, 67, 275-301.

Roche, B., Barnes-Holmes, D., Smeets, P. M., Barnes-Holmes, Y., \& McGeady, S. (2000). Contextual control over the derived transformation of discriminative and sexual arousal functions. The Psychological Record, 50, 267-291.

Skinner, B. F. (1945/1972). The operational analysis of psychological terms. Reprinted in Cumulative record: A selection of papers. New York: Appleton-Century-Crofts. (Originally published in Psychological Review in 1945)

Skinner, B. F. (1957). Verbal behavior. New York: Appleton-Century-Crofts.

Skinner, B. F. (1966). An operant analysis of problem solving. In B. Kleinmuntz (Ed.), Problem-solving: Research, method, and theory (pp. 225-257). New York: Wiley.

Smeets, P. M., \& Barnes-Holmes, D. (2003). Children's emergent preferences for soft drinks: Stimulus-equivalence and transfer. Journal of Economic Psychology, 24, 603-618.

Society for Industrial Organizational Psychology Web Page (March, 2005). Retrieved from http://www.siop.org/media/talking.htm on July 25, 2005

Titchener, E. B. (1916). A text-book of psychology. New York: MacMillan.

Whelan, R. (2004). Motivation: A relational frame theory analysis. Unpublished doctoral dissertation. National University of Ireland, Maynooth.

Whelan, R., \& Barnes-Holmes, D. (2004). A derived transformation of consequential functions in accordance with the relational frames of same and opposite. Journal of the Experimental Analysis of Behavior, 82, 177-195.

Wiegand, D. M., \& Geller, E. S. (2005). Connecting positive psychology and organizational behavior management: Achievement motivation and the power of positive reinforcement. Journal of Organizational Behavior Management, 24, 3-25.

doi:10.1300/J075v26n01_01 